\title{
GROWTH RATE INHIBITION OF SOME SPOILAGE FUNGI OF FOOD BY MAGNETIC FIELD
}

\begin{abstract}
A. E. Abdelhameed*
ABSTRACT

The main objective of this paper was to study the inhibitory effects of static and oscillating magnetic field on growth rate of pathogenic fungus for extending the shelf life of food. The treatment of various food material with the static or oscillating magnetic field reduces the growth rate of the different selected fungus species. The spoilage fungi used to experiments procedure were include the specie of Plasmopara viticola, Rhizopus stolonifer, Asperguillus niger and Rhizopus nigricans was isolated respectively from cheese, apple, bread. Some fungus were more sensitive to the magnetic field. The effect of oscillating magnetic field was more active compared with static magnetic field with the same exposure times. The inhibition rate of fungus was increased in both static and oscillating magnetic fields percent of the control, this relative increase was larger than $55 \%$ with static magnetic field after $120 \mathrm{~h}$ at $0.4 \mathrm{~T}$ and $72 \%$ with oscillating magnetic field after $120 \mathrm{~h}$ at $0.25 \mathrm{~T}$.
\end{abstract}

\section{INTRODUCTION}

$\mathrm{F}$ Tungal infections of foods such as fruits, vegetables, bread, meat and dairy products may occur during the handling, transport, storage and marketing conditions and after purchase by consumers. The magnetic field technology will be useful in inactivating the microorganisms without any detectable change in quality and shelf life compared to conventional pasteurization process (Barbosa et al., 1998). The application of static or oscillating magnetic field might be used in disinfecting agricultural products and food. The traditional methods of food preservation though guarantees its safety, sometimes cause loss of sensitive nutrients, denaturation of proteins as well as changes of structure, colour and taste. The non-thermal methods preserve the nutritious value of food and at the same time, reduce threat by spoilage organisms.

\footnotetext{
* Lect., Agr. Eng., Fac. of Agr. Eng Al-Azhar Univ., Cairo.
} 
The antimicrobial effect of exposure to electromagnetic field is not due to the temperature effect, but rather its ability to cause damage to the cell structure and composition. Results of previous studies have confirmed the inhibition of microorganisms when placed in electromagnetic fields and inhibitory effect on microbial population (Lipiec et al., 2004). The main objective of this study was to evaluate the inhibitory effects of static and oscillating magnetic field on growth rate of pathogenic fungus for extending the shelf life of food as non-thermal method for food preservation without any change in food properties. Moulds and yeasts are significant spoilage organisms of food and feed. Inaddition, the potential production of toxic and carcinogenic mycotoxins by mouldsis of particular concern. Besides this problem, fungal spoilage of food also causes significant economic losses. Worldwide, about 5-10\% of the food production is estimated to be spoiled by these organisms (Pitt \& Hocking, 1999). Moulds belonging to the species Penicillium, such as P. commune, P. nalgiovense and P. roqueforti commonly spoil various foods as cheese, bread and meat products (Lund, et al. 1995). Aspergillus sp. and Penicillium sp. frequently occur as spoiling organisms during storage of grain, whereas Fusarium sp. are the most common spoilage fungi of crops in the field (Filtenborg, et al. 1996). Sadauskas et al. (1987) examined the effect of $200 \mathrm{mT}$ flux density static and 29 $\mathrm{mT}$ flux density pulsating magnetic field on the different species of fungi. According to their examination, morphological changes were observable on the conidia of Aspergillus puniceus and Alternaria alternata. The pigmentation of the colony of Aspergillus niger changed, the cultures remained white. The effects of weak magnetic fields on the growth and membrane lipid ergosterol of mycorrhizal fungi Pisolithus tinctorius were studied. Two types of media were used: solid ( $\mathrm{pH} \mathrm{6)}$ and liquid $(\mathrm{pH} 3)$. The homogenous sinusoidal magnetic field, generated by a pair of Helmholtz coils with magnetic flux density 0.025 and $0.1 \mathrm{mT}$ and frequency of $50 \mathrm{~Hz}$ enhanced the growth of mycelia at early stages of development. The same field at $0.01 \mathrm{mT}, 46 \mathrm{~Hz}$ had no observable effects. Analysis of the fungi specific membrane constituent ergosterol by high performance liquid chromatography reveals a slightly increased content of ergosterol in the mycelia (along with the observation of 
stimulated growth). The results indicate some importance of the membrane which is most probably the acceptor of electromagnetic signals, as has been revealed by many studies with animals. However, more exact mechanisms for the explanation of these effects are not known yet. (Ruzic et al. 1997).

\section{MATERIALS AND METHODS}

The spoilage fungi used in this study include the species of Plasmopara viticola, Rhizopus stolonifer, Asperguillus niger and Rhizopus nigricans were isolated respectively from cheese, apple, bread. The inoculums for experiments were taken from the spoilage food material and grown on the same nature food material. The cultures were incubated for 48 hours after the inoculation at $25-33^{\circ} \mathrm{C}$. After the incubation the cultures, uniform from the point of view of growing and morphology, were placed into the magnetic field. To investigate of the effect of a magnetic fields on the fungi growth, the magnetic field was generated by a long coil of wire consisting of many loops (solenoid). If the turns are closely spaced, this configuration can produce a reasonably uniform magnetic field within a small volume of the solenoid interior region. Each of the turns can be regarded as a circular loop, and the net magnetic field is the vector sum of the fields due to all the turns. If $N$ is number of turns in the length $l$ (Fig. 1). Therefore, Amperes low applied to this path gives:

$$
B=\frac{\mu_{o} N I}{l}=
$$

where: $B$ is the magnetic flux density $(T)$

$\mu_{o}$ is permeability of free space $\left(\mathrm{N} / \mathrm{A}^{2}\right)$

$I$ is the electrical current (A).

For the present experiment two types of the magnetic field wear generated, static magnetic field (SMF) (generated by directed current) or oscillating magnetic field (OMF) (generated by alternating current) with low frequency 50/60 Hz. The solenoid was made with $7 \mathrm{~cm}$ length and $10 \mathrm{~cm}$ diameter. The coil was made from enameled copper wire of $2 \mathrm{~mm}$ diameter with 1000 turns. The copper wire of $3.14 \mathrm{~mm}^{2}$ cross section could be loaded by the current of $8 \mathrm{~A}$, which means a magnetic flux 
density up to $0.4 \mathrm{~T}$ SMF and $0.25 \mathrm{~T}$ OMF. The magnetic flux density has been changed by a change of loading current according to the previous equation .In the course of experiments, the ambient temperature of 28$33^{\circ} \mathrm{C}$ and relative humidity $45-50 \%$ were the same for the control and the treated cultures. The diameters of the growing cultures were measured every 24 hours in two directions, perpendicular each other. The average of this two diameters was used as the diameter of the culture. The growth of fungi followed the well known logistic function. The middle part of this function can be fitted by a straight line (Wilson and Bosset 1981). A straight line was fitted for the average diameters with the help of Excel program, and the growth speed in $\mathrm{mm} / \mathrm{h}$ was calculated as a slope of straight line (Nagy P., 2005).

\section{Experimental set-up}

Samples were placed on a dielectric holder in the center of the coil, where the magnetic field is a reasonably uniform. All samples were made in three replicates and treatment with three value of magnetic field $0.1,0.25$ and 0.4 T magnetic flux densities of SMF and 0.05, 0.15, 0.25 T of OMF with 24, 48, 72, 96 and $120 \mathrm{~h}$ exposure time of SMF and OMF.

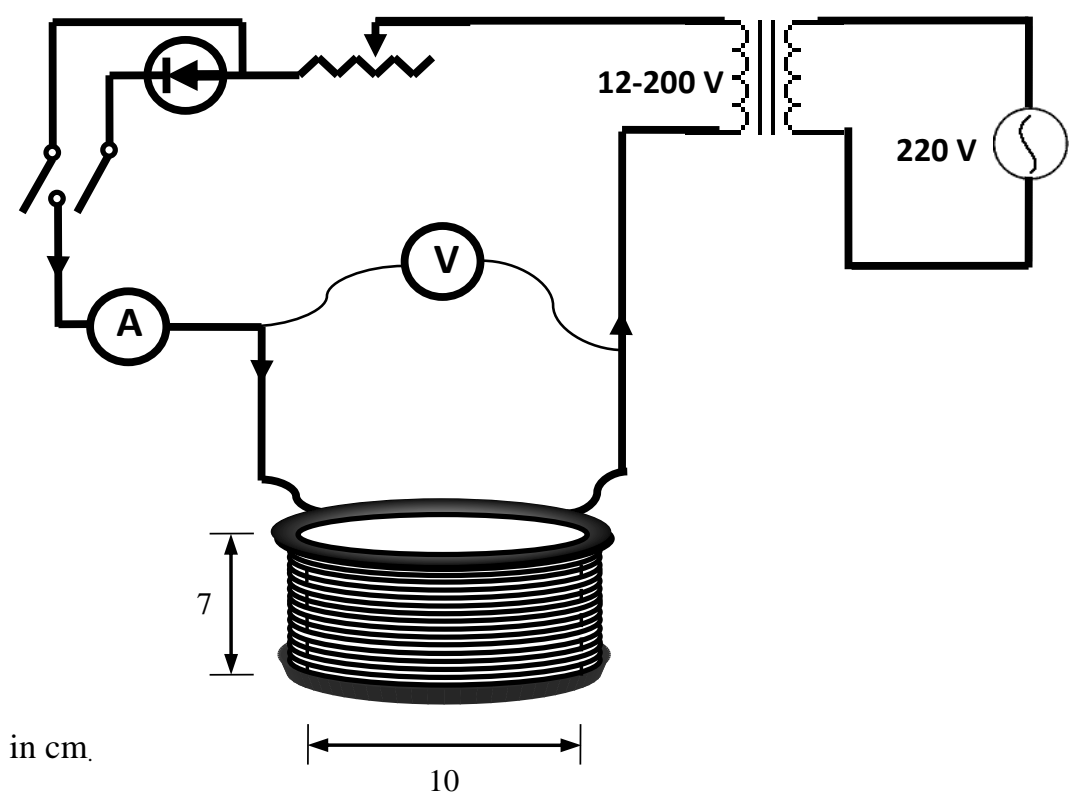

Fig. (l): Schematic diagram of experimental set up. 


\section{Rate of fungus inhibition:}

Rate of fungi growth is usually attributed to control, the following equation was originated to calculate the rate of fungi inhibition (FI) percent:

Where:

$$
\mathrm{FI}(\%)=100-\left(\frac{\mathrm{a}_{\mathrm{M}}-\mathrm{a}_{\mathrm{I}}}{\mathrm{a}_{\mathrm{C}}-\mathrm{a}_{\mathrm{I}}} \times 100\right)
$$

$$
\begin{aligned}
& \mathrm{a}_{\mathrm{M}}=\text { growing area of fungi with the magnetic field } \\
& \mathrm{a}_{\mathrm{C}}=\text { growing area of fungi of control } \\
& \mathrm{a}_{\mathrm{I}}=\text { Initial growing area of fungi }
\end{aligned}
$$

The area was calculated by mean diameter measurement all $24 \mathrm{~h}$.

\section{RESULTS AND DISCUSSION}

The growth speed of the all examined pathogen fungi cultures were decreased in both static and oscillating magnetic fields. The fungus inhibition (FI) was calculate from equation (2).

\section{Effect of static magnetic field}

The growth rate of the different fungus species in the static magnetic field 0.1, 0.25 and 0.4 T magnetic flux densities are shown in Figs (2a) and (3). The increasing of magnetic flux density leads to increase inhibition of fungi (FI), fungus Plasmopara viticola were more sensitive to the static magnetic field effects, where the relative increase in inhibition of fungi (FI) was increased up to $21 \%, 36 \%$ and $57 \%$ percent of the control after $120 \mathrm{~h}$ with increasing of magnetic flux densities of $0.1,0.25$ and $0.4 \mathrm{~T}$ respectively, and the less effect of the static magnetic field with fungus Asperguillus niger. where FI was $11 \% \quad 26 \%$ and $47 \%$ after $120 \mathrm{~h}$ with increasing of magnetic flux densities $0.1,0.25$ and 0.4 $\mathrm{T}$ respectively. Fig (3) shows that the inhibition rates of fungus growth of all species was increased with increasing the exposure time of SMF $(24,48,72,96$ and $120 \mathrm{~h})$. With increasing the time from $24-120 \mathrm{~h}$, FI was increased from $4-15 \%, 7.5-28 \%$ and $11-50 \%$ with Rhizopus nigricans and $3-12 \%, 9-32 \%$ and $10-56 \%$ with Rhizopus stolonifer at $0.1,0.25$ and $0.4 \mathrm{~T}$ respectively. The inhibition of microorganisms when subjected to the magnetic field may be attributed 
to transfer of energy to the ions of the cells, results in an increase in the velocity of ions such as $\mathrm{Ca}^{2+}$ across the cell membrane, the changes occur in the metabolic activities of the cells. The ions transmit the effects of magnetic fields from the interaction site to other tissues and organs.

\section{Effect of oscillating magnetic field}

The oscillating magnetic field applied in this study proved to be effective in reducing the growing of fungus, the tests on the selected fungus are less satisfactory. Figs. (2b) and (4) show the inhibition of fungus "FI" (\%) with increasing of oscillating magnetic flux density from zero $\mathrm{T}$ to $0.05,0.15$, and $0.25 \mathrm{~T}$, also with increasing the exposure time of OMF $(24,48,72,96$ and $120 \mathrm{~h})$, fungus inhibition "FI" (\%) percent of the control was increased up to 53, 65, 69 and $72 \%$ respectively after $120 \mathrm{~h}$ of the different fungus species. Observe that the inhibition rate of fungus with oscillating magnetic field was more active compared with static magnetic field. This may be attributed that the oscillating magnetic field cause anisotropically vibrates of ions and altering the vibrational structure of enzymes.

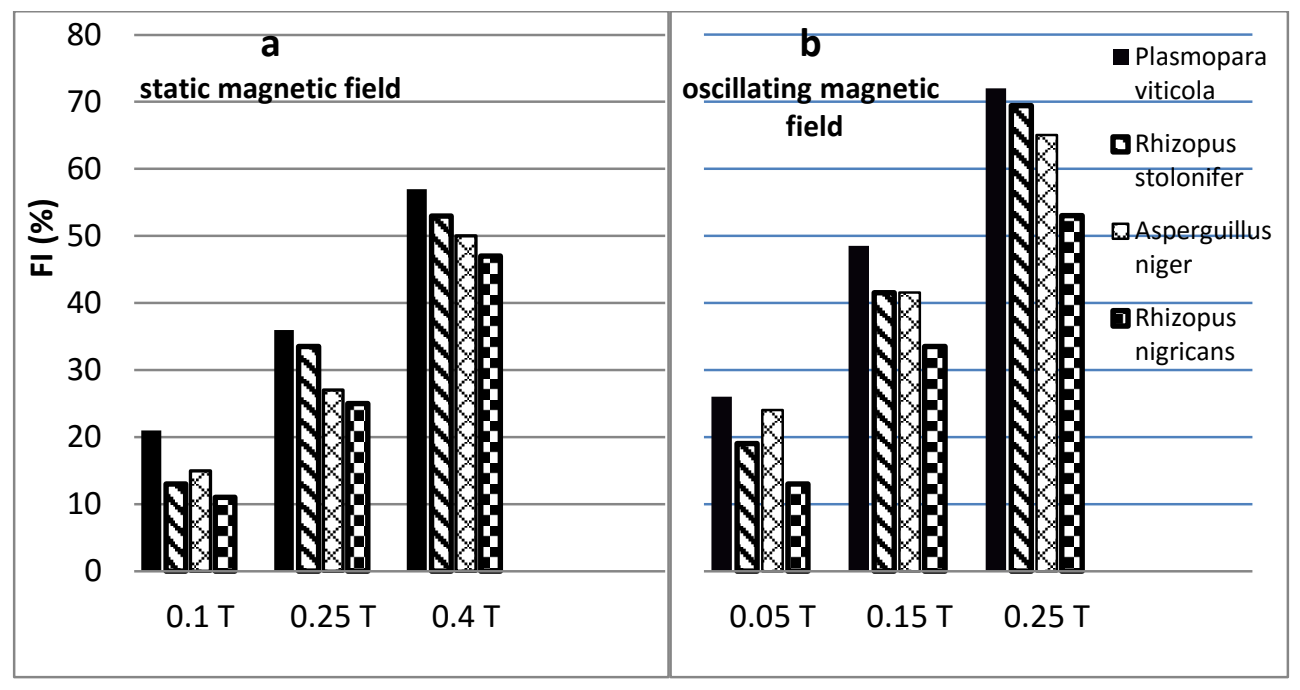

Fig. (2): Effect of magnetic field on inhibition of different Fungi species "FI" (\%) after $120 \mathrm{~h}$. 
(Plasmopara viticola)

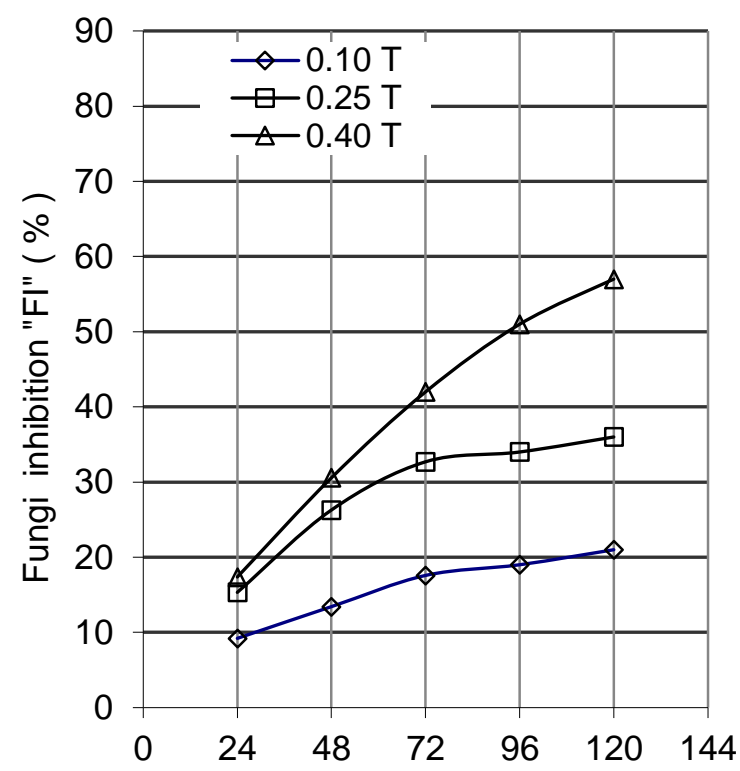

\section{(Rhizopus nigricans)}

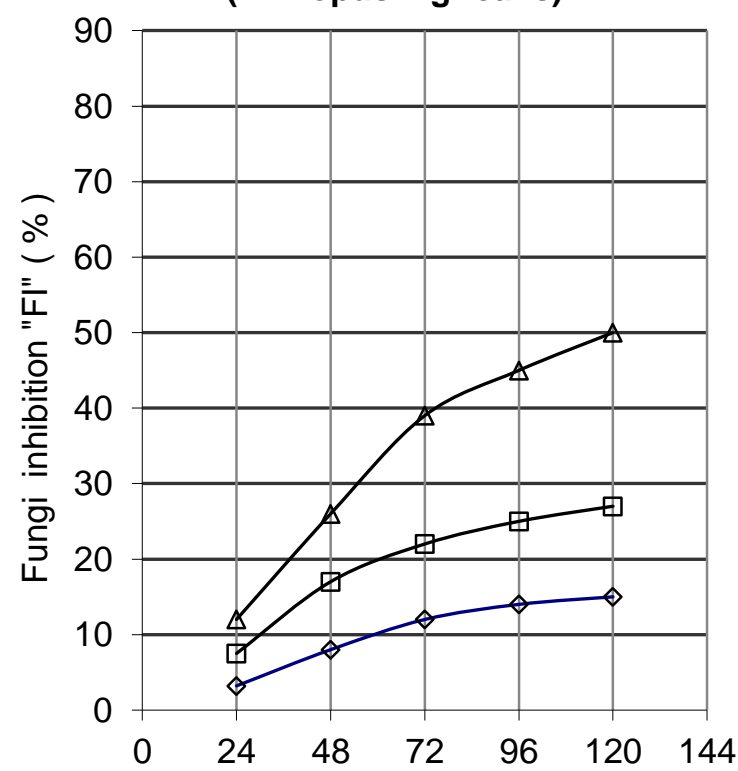

(Rhizopus stolonifer)

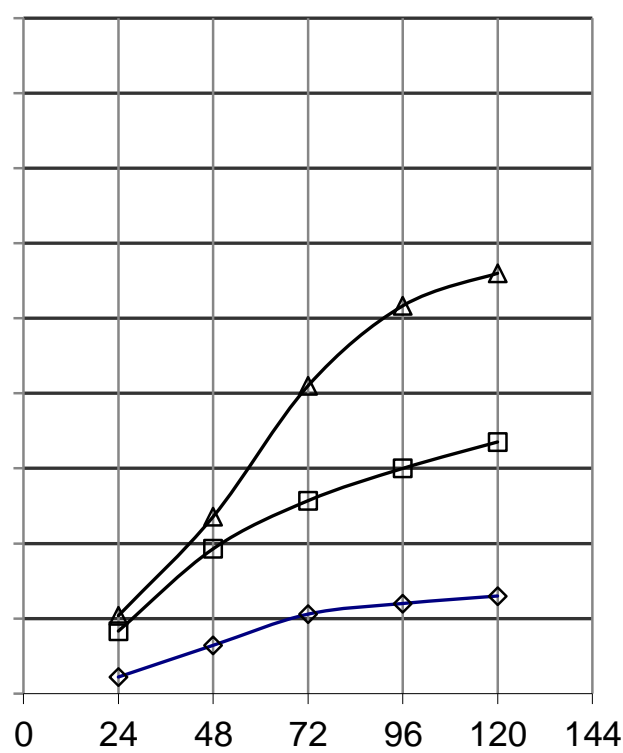

(Asperguillus niger)

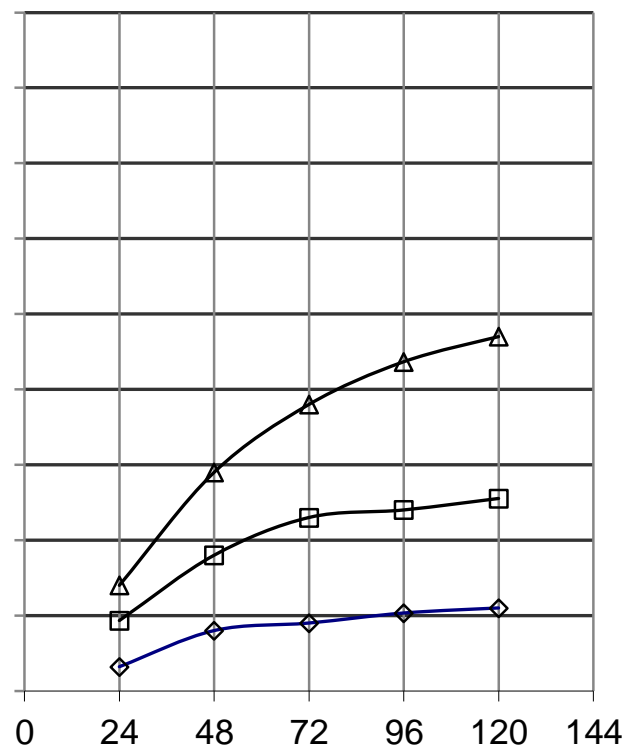

Time (h)

Fig.(3): Effect of exposure time of static magnetic field on Fungi inhibition "FI" (\%) 
PROCESS ENGINEERING

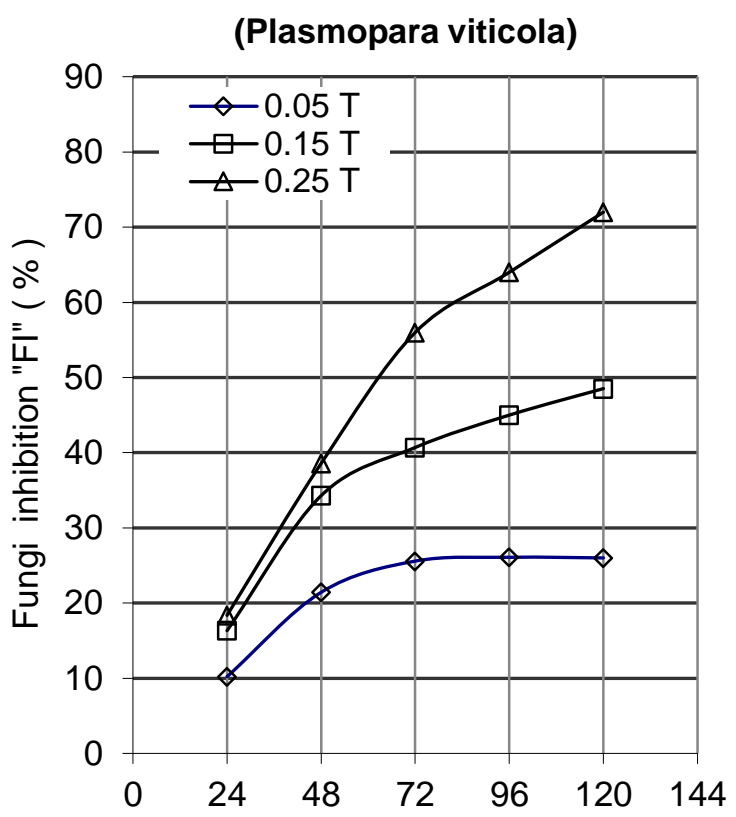

(Rhizopus stolonifer)
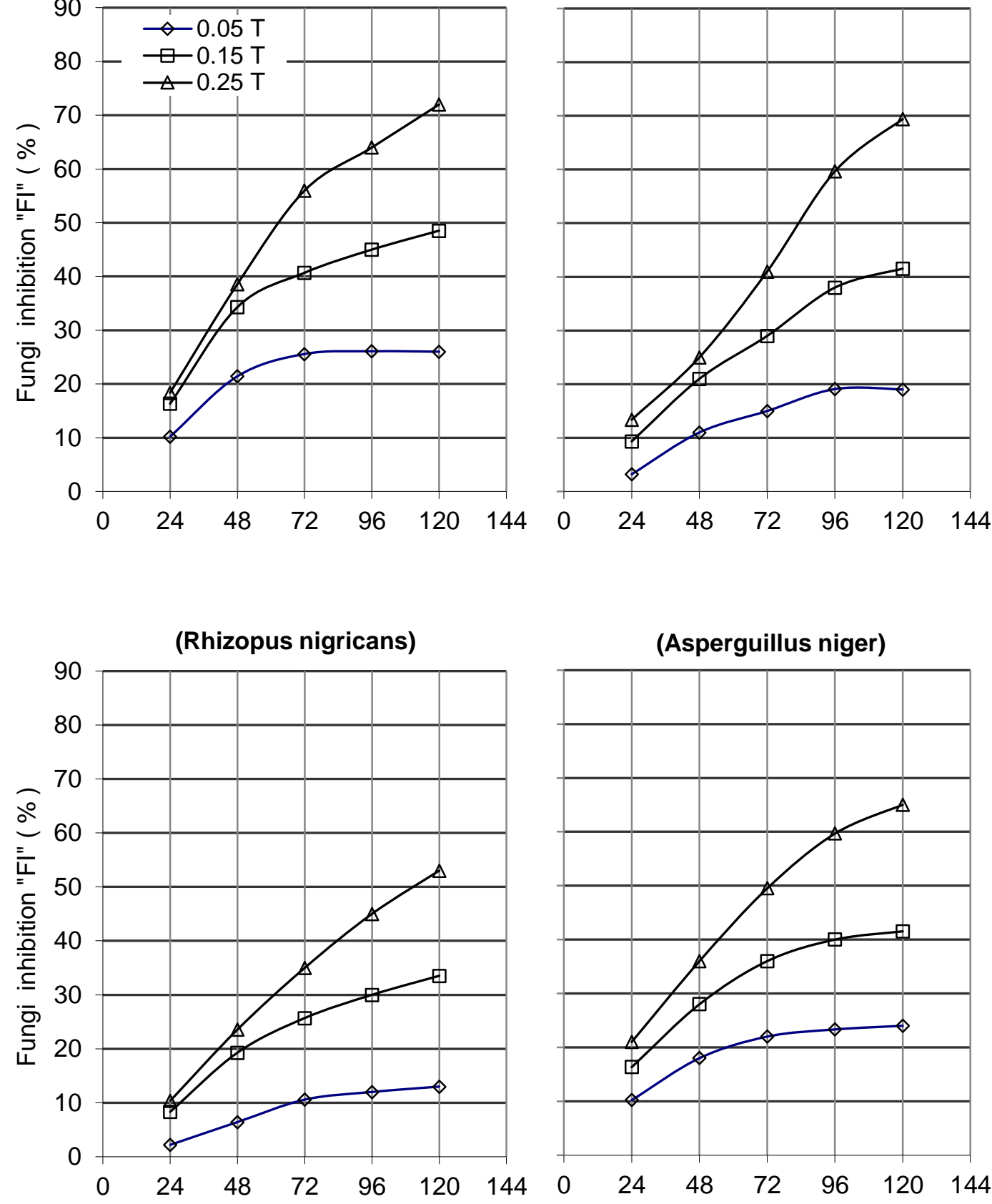

Time (h)

Fig.(4): Effect of exposure time of oscillating magnetic field on Fungi inhibition "FI" (\%) 


\section{CONCLUSIONS}

The treatment of various food materials with the static or oscillating magnetic field reduces the growth rate of the different selected fungus species. Some funguses were more sensitive to the magnetic field. The effect of oscillating magnetic field was more active compared with static magnetic field with same exposure times. The inhibition rate of fungus percent of the control reach $5 \vee \%$ with static magnetic field and $72 \%$ with oscillating magnetic field. The growing of fungus in the magnetic field may be stop by using high intensity of static or oscillating magnetic field with increasing the exposure time.

\section{REFERENCES}

Barbosa, G.V., Pothakamury U.R., and Swanson B.G., (1998). Nonthermal Preservation of foods (Oscillating magnetic field). Marcel Dekker, New York: 113-135

Filtenborg, O., Frisvad, J.C. \&Thrane, U. (1996). Moulds in food spoilage.International Journal of Food Microbiology 33: 85-102.

LIPIEC, J., JANAS, P. and BARABASZ, W. (2004). Effect of oscillating magnetic field pulses on the survival of selected microorganisms.In International Journal ofAgrophysics, 18: 325-328.

Lund, F., Filtenborg, O. \&Frisvad, J.C. (1995). Associated Mycoflora of Cheese. Food Microbiology, 12: 173-180.

Nagy P. (2005). The effect of low inductivity static magnetic field on some plant pathogen fungi. Electro. And Magnetobiology, 11: 152-163

Pitt, J.J. \& Hocking, A.D. (1999). Fungi and food spoilage. Second ed. Aspen Publications: $122-133$

Ruzic R., Gogala N. and Jerman I. (1997) Sinusoidal magnetic fields: effect on the growth and content of ergosterol in mycorrhizal fungi. Electro. Magnetobiol. 16(2): 129-142. 
Sadauskas K. K., Lugauskas A. Y. and Mikulskene A. I. (1987). Effects of constant and pulsating low-frequency magnetic field on microscopic fungi. Mikologija I Fitopatologija 21: 160-163.

Wilson E. O. and Bosset W. H. (1981). Bevezetés a populációbiológiába (A Primer of Population Biology). Budapest: Gondolat,: 130-133

$$
\text { الملخص العربي }
$$

تثبيط نمو بعض الفطريات المسبية لفساد الأغذية بإستخدام المجال المغناطيسى

$$
\text { عبد الحميد السعيد* }
$$

تمثل الفطريات أحد أهم مسببات الفساد للمو اد الغذائية ويحدث الثلوث الفطري أثناء الحصاد و النقل

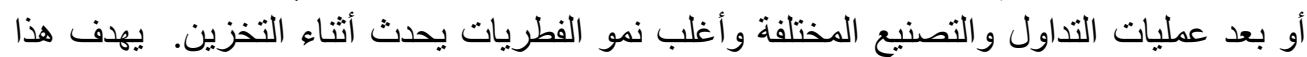

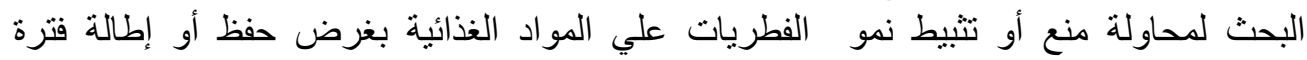

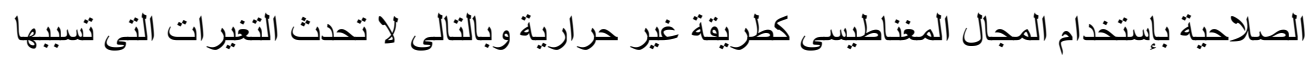

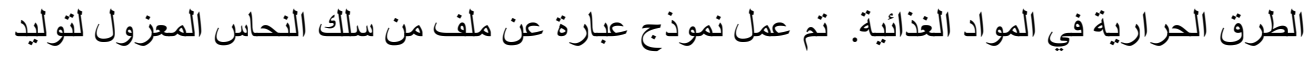

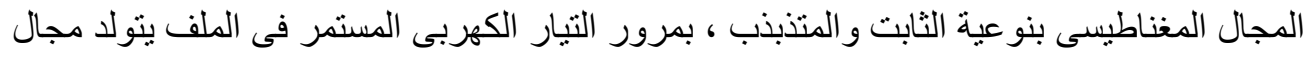

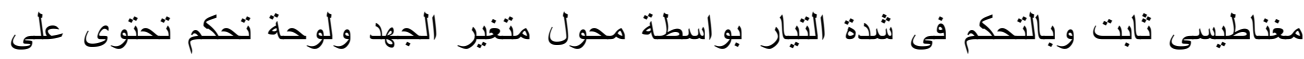

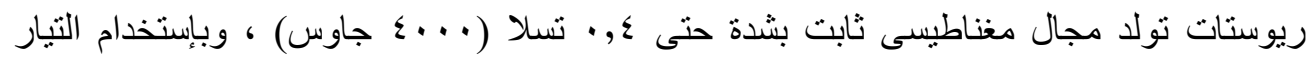

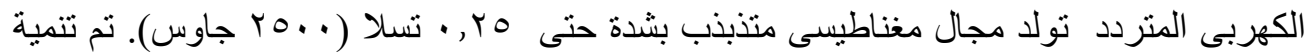
أربعة أنواع من الفطريات هى: Phizopus stolonifer و و Rhizopus nigricans و Asperguillus niger

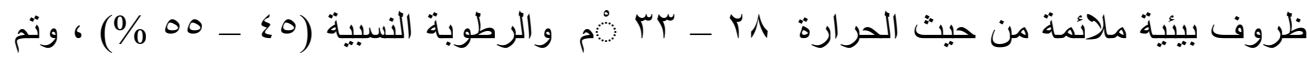

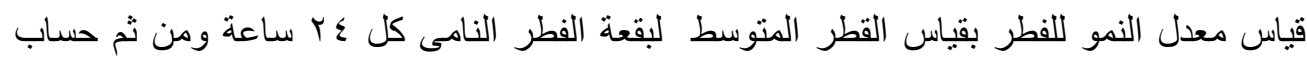

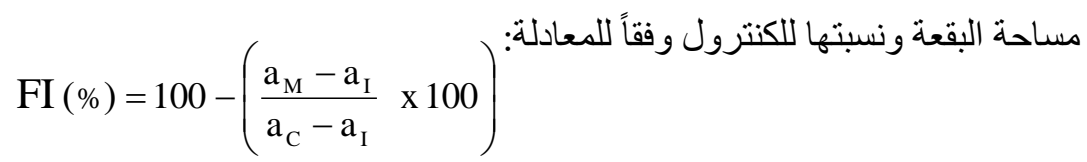

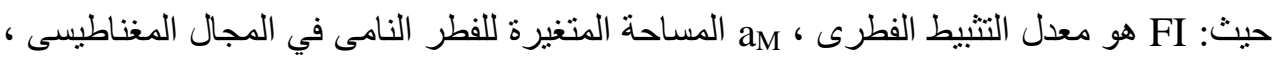

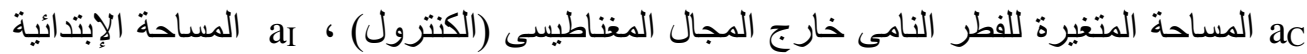

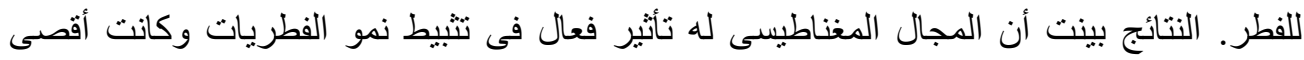

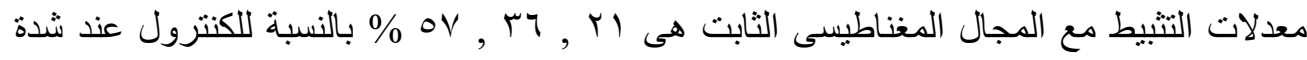

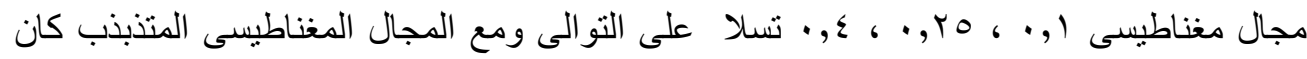

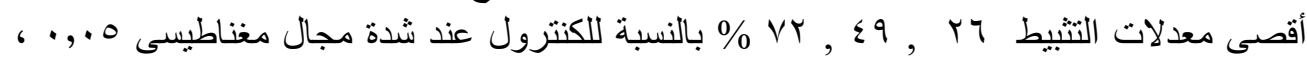
10 10

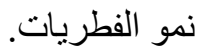

